\title{
Study on the Foreign Language Education for the Ethnic Minorities in Northern China from the Perspective of Trilingual Acquisition*
}

\author{
Shuang Lv \\ General Education College \\ Heihe University \\ Heihe, China 164300
}

\begin{abstract}
Ethnic minorities in northern China have a positive attitude towards trilingual education, which is favorable for the foreign language education there. Compared with "bilingual acquisition", "trilingual acquisition" shows the characteristics of language attrition and reversal, the complexity of interdependence, and the cognitive superiority of languages. The complicated cognitive process of trilingual acquisition leads to the particularity of the educational process. By analyzing the problems met by the minority students in the process of foreign language learning in northern China, educators are suggested to make full use of the bilingual advantages of the minorities, pay close attention to preserve their language proficiency and carry out the study of interlingual transfer, so as to promote the foreign language education in this area.
\end{abstract}

Keywords-trilingual acquisition; ethnic minorities in northern China; foreign language education

\section{INTRODUCTION}

"Trilingual acquisition" refers to one or more languages that are currently learned, except for the mother tongue of the learner and the second language that has been mastered. [1] Because China is a multinational country, foreign language teaching for minorities mostly experiences a process from mother tongue and Chinese to foreign language. However, we seldom study the learning process of these special learners from the perspective of trilingual acquisition. In the course of teaching, whether the syllabus, the compilation of the textbook or the actual classroom teaching, is basically carried out in Chinese language and cultural background. The ethnic minorities, which account for nearly $10 \%$ of the total population of the country, differ greatly from the Han people in terms of their geographical environment, cultural background, language use, religious beliefs, living habits and thinking modes. Obviously, it is inappropriate that foreign language education in minority regions is based on such theory and methods as Chinese

*Fund Project: The research planning project of Philosophy and Social Science in Heilongjiang province The Research on the Problems and Countermeasures of Minorities' Foreign Language Education in Heilongjiang Province from the Perspective of the Belt and Road Initiative (Project No.:17YYE419) language, while neglecting the influence of their mother tongue. In China, the English proficiency of minority students is generally poor, which not only seriously frustrates the enthusiasm of minority students to learn foreign languages, but also is unfavorable to the national cohesion. Therefore, it is necessary to establish a trilingual teaching and researching system in the multilingual and multicultural background in our country, which is essential to guide the foreign language education of ethnic minorities and improve the language proficiency of the minority students. Due to the historical development and geographical position, the ethnic minorities in northern China have their own characteristics in trilingual acquisition and cognition. Therefore, it is advisable to make a clear layout for its foreign language education with a better understanding of the above and the following conditions.

\section{THE RECOGNITION OF THE THREE LANGUAGES IN NORTHERN MINORITIES}

There are 10 ethnic minorities living in the north of China, including the Mongolian, Hui, Korean, Manchu, Daur, Kirgiz, Xibe, Ewenki, Oroqen, Hezhen and other ethnic groups. Seven of them have bilingual phenomena except the Manchu, Hui and Xibe. In receiving education, the third language-English, Russian, Japanese, French, German, Korean and so on offers them the competitive advantage of language, and the learners have a better recognition of trilingual education.

The ethnic minorities living in the northern part of our country mostly approve the trilingual education and can take it objectively, thinking that there are internal relations between three languages, and hoping that the language teachers can have a good command of three languages.[2] The reason is that the ethnic minorities living in the north, such as the Mongolian, Korean and Kazakh, not only have their own ethnic language and words, but also have an education system in school involving three languagesnative language, Chinese and foreign language. Compared with the other ethnic minorities in the western area, the northern minorities received higher education of the three languages, and accordingly, the students have higher trilingual proficiency and are more confident in becoming 
language talents in society. Secondly, some ethnic minorities live in a more open area and exchange frequently with the border countries in economy and culture. Hence, with the trilingual knowledge and competency, the ethnic people there have their own advantages. For most northern minorities, the three languages background of the people is a competitive force, with which they can make full use to serve as bridges and platforms among the inter ethnics, ethnic groups and the nations. Every language, as a social productive force, can produce social benefits. The minority students with three languages have gained social recognition from the social benefits produced by the three languages. They recognize the benefits of the three languages education, which provides a realistic motive and a developing necessity for the teaching of the third language. Only when we understand how the foreign language, that is, the third language, is showed and processed in the students' minds, can we organize students to learn foreign language effectively.

\section{The Cognitive Process AND CHARACTERISTICS OF TRILINGUAL LEARNING}

Once the learners have mastered two languages, the two languages will play an important role in the learning process of the third language, and the language that the learners have mastered is the object of transfer. [3]A series of studies have found that language distance is the most important factor affecting the production and acquisition of the third language. In other words, if the source language and the target language are closer in type, the more likely it is to borrow vocabulary from the third language, and the more content words it borrows compared with the functional words. In addition, the role and position of second language in trilingual acquisition is also influenced by language distance. The closer the second language is to the target language, the more likely the learners will be able to use the second language. The researchers also found that the factors affecting trilingual acquisition include certain contexts of the discourse, the language proficiency of the learners, and the time sequence of learning foreign languages. Learners in lower level borrow more vocabularies from first language, and multilingual learners are more likely to use newly acquired language.[4] All these shows the complex interdependence of three languages. Language transfer in trilingual acquisition is multi-dimensional and complicated. It is not only restricted by the macro social and cultural factors such as language environment, language contact, language policy and language planning, but also by the learners' age, gender, linguistic proficiency, linguistic background, learning style, or cognitive style, together with the external factors such as individual factors and verbal communication context.

Language development shows three main characteristics: First, language attrition. It refers to the phenomenon that the native speakers lost part of their native language proficiency because of long-term living in the second language environment, and the degradation of the proficiency and knowledge of the second language or foreign languages, which happens after receiving several sessions of language training.[5] Therefore, multilingual learners need more efforts to maintain the new language proficiency. Second, the complexity caused by mutual dependence. Interdependence refers to the interaction between languages in the learner's language system. When learners have mastered two languages, these two languages will have an impact on the learning of the third language, and the original knowledge may become the object of transfer.[6] In multilingual environment, the background language in the learner's brain is activated and competing. In phonetics, almost all trilingual language learners and even advanced learners retain their accents of the first language in pronunciation and intonation. Third, the dominance of cognitive language. Multilingual learning can polish a speaker's linguistic system, and the acquisition of an additional language will develop new skills, including language learning skills, management skills, and maintenance skills. [7]

Therefore, the foreign language education of ethnic minorities should not only take into account the general rules and principles of foreign language teaching, but also pay close attention to the process and characteristics of the trilingual acquisition so as to discover the problems in language teaching and solve them.

\section{The PRESENT SituAtion OF THE TRILINGUAL}

\section{EDUCATION OF ETHNIC MINORITIES IN NORTHERN CHINA}

In recent years, foreign language education for ethnic minorities in northern China has made some achievements. Many ethnic schools are active in foreign exchanges with schools both at home and abroad for education experience. It has promoted the academic exchanges between teachers and students of ethnic minorities with other foreign nations. These activities help to draw on and learn the advanced educational concepts and achievements of various nations and countries, to share teaching resources and to improve the teaching effects of the third language. But there are still some problems in the process of trilingual education.

Firstly, there is no special foreign language teaching material compiled on the characteristics of the students with three languages background. The cultivation of teachers with three languages background lagged behind the realistic demand. The teachers, who engaged in trilingual education for ethnic minorities, are in shortage, and the highly qualified teachers were difficult to seek.

Secondly, most of the minority learners who grow up in their ethnic habitat experience a process from mother tongue, Chinese to foreign language in trilingual acquisition. Most of them enter the university with limited foreign language proficiency, less vocabulary, poor oral expression, and lack of reading ability. Foreign language teachers are mainly Han teachers and do not understand minority languages, so they have problems in understanding students' learning process and learning difficulties.

Thirdly, in the actual foreign language teaching, the majority of the minority students still receive the same foreign language teaching mode as the Han students. The language learning experience and cognitive advantages 
obtained from the bilingual education have been neglected instead of fully developed.

Fourthly, minority students speak their native language at home, speak Chinese or native language at schools, and barely speak foreign languages. In their daily life, they have less opportunity to practice it, which is unfavorable for foreign language learning. Consequently, language attrition arises. While less attention is paid to the language attrition and the interference of the first and second language in the current curricula, teaching plans and teaching activities of the third language education, which is unfavorable to the consolidation of new language.

Finally, ethnic minority students are interfered by both mother tongue and Chinese in the process of learning foreign language, and negative transfer of language becomes one of the big obstacles to their learning. In recent years, the research on the transfer of mother tongue in China mainly consists of the language transfer of Chinese to English and the language transfer of the minority language to the Chinese language. There are few studies on the influence of minority languages on English learning. These factors confine the development of the foreign language education of the ethnic minorities in the north of China.

\section{FOREIGN LANGUAGE EDUCATION PLANNING FOR ETHNIC MINORITIES IN NORTHERN CHINA}

The planning of foreign language education for minority areas must take full account of the different roles that foreign languages plays in the political, economic and cultural constructions in different regions, and take the preservation of the citizens' mother tongue as a premise. Language education should not only conform to the "great unification" of the Chinese nation and make contribution to the internationalization of Chinese culture, but also maintain the local culture of the ethnic minorities. [8] Considering the complicated language, social, psychological and cultural factors involved in learning foreign languages in minority areas, it is inappropriate to regard it as an ordinary foreign language learning. The minority language teaching should be studied and discussed in the perspective of the second and third language acquisition theory.

\section{A. Making Full Use of the Cognitive Advantage of Regional Language}

In the process of multilingual learning, the cognitive advantages of minority students provide inspiration for the formulation of foreign language education policy and the organization of foreign language teaching. Based on the reality, the policy should be made to integrate the characteristics of the cognitive advantages in the multilingual learning process of the minority students and the actual situation of the foreign language teaching in the minority areas of our country. It's advisable to establish a foreign language education system and curriculum which are particularly suitable for them. Language category is the key factor to promote learners' metalinguistic awareness. The closer the type of the language is, the easier it is to facilitate language transfer, accordingly promoting the development of learners' metalinguistic awareness. [9]Therefore, it is suggested that closer languages, in culture and location, should be taught in ethnic minority areas. It is relatively easy for the minority students in these areas to learn these languages. If they further study the professional knowledge of economy, management and tourism, they will be comprehensive international talents.

The organization of teaching activities should also follow the characteristics of trilingual learning. In the course of teaching, we should pay attention to combine the explanation of language knowledge and the practical use of language, and design teaching activities that can help the students' metalinguistic consciousness further developed and fully utilized. The teaching activities are designed on the learning and exploration of the minority students, giving full play to their learning experience accumulated in multilingual learning, and respecting their subjectivity.

\section{B. Paying Attention to the Maintenance of Foreign Language Proficiency}

Educators should not only encourage minority students to learn foreign languages, but also focus on maintaining their foreign language proficiency. Although the third language is affected by the first and second languages, its process can be slowed down otherwise. First of all, as a foreign language teacher, we should help students understand the principles of foreign language attrition and memorization, train and guide students to learn strategically and find ways to maintain their language proficiency. Secondly, the textbook compilers should follow the principle of memorization and forgetting in the compilation of teaching materials. The more familiar with the learning material is, the easier it is to collide and connect with the original knowledge, experience and emotion, and then the learning materials will be fully and accurately remembered. The input and output of language play a key role in the preservation of language. Therefore, the selection of classroom learning materials should be abundant, realistic, and close to the life of the learners. For the trilingual language learners in northern regions, it is suggested that special foreign language teaching materials should be written to introduce the domestic rural life, the classic culture of ethnic minorities, the cultural landscape, the customs, the folk songs, the dances and so on, besides western culture. Finally, as for the teaching method, learners are encouraged to introduce their own native culture. The culture contrast of each ethnic group, the contrast of the Chinese and the western culture, the field study and other methods will involve students in the teaching activities. These practical learning tasks enable the learners to analyze and process the language information more deeply, thus helping to keep the knowledge in long-term memory.

\section{Carrying out Researches on Trilingual Transfer}

Compared with the transfer in mother tongue and second language acquisition, the trilingual acquisition is more complicated because of the influence of the former two. In the trilingual acquisition process, it is valuable to study how the third language influences and transfers in the minority learners' phonetics, syntax, vocabularies, pragmatics and so 
on. It is also helpful to study the acquisition of nonhomologous languages in cross-cultural environment.

\section{CONCLUSION}

With the progress of global integration, talents with multilingual language proficiency have serve as a communicative bridge and platform among cultures. Multilingual competence is one of the most competitive features. [10]The ethnic minorities with trilingual background and multiple cultures are natural treasure of human resources. It provides valuable language basis and empirical basis for the training of trilingual or multilingual proficiency. For a long time, we have been teaching minority students in way of teaching Han students to learn foreign language, ignoring the differences that minority students may have in social environment, language, culture background, psychological cognition development and thinking mode. There is a lack of thorough study of the characteristics and principles of foreign language learning. Therefore, it is necessary to study it further, especially for minority students with multilingual and multicultural background, so as to revolutionize the teaching and researching in a scientific way, and improve the quality of foreign language education in ethnic areas, which bears realistic and strategic significance.

\section{REFERENCES}

[1] Fouser R. Problems and Prospects in Third Language Acquisition Research [J]. Language Research,1995: 31.

[2] Zhang Zhen-ai, Yu Chun-xi. A Study on Identification with Trilingual Education of Ethnic Minority Teachers and Students in Northern China [J].Journal of Research on Education for Ethnic Minorities, 2012, (1)22.

[3] Cohen A D. In Which Language do/should Multilinguals Think [J]. Language, Culture, and Curriculum, 1995, (8).

[4] Odlin, T. Language Transfer-Cross-linguistic Influence in Language Learning [M]. Shanghai: Shanghai Foreign Languages Education Press, 2001.

[5] Tan Aihua. The Phenomenon of Trilingual Transfer in the Theory of Language Processing and Its Enlightenment to the Foreign Language Teaching of Ethnic Minorities [J]. Journal of Southwest University for Nationalities (Humanities and Social Science Edition), 2012, (1) 220.

[6] Cai Hansong, Zhou Rong. On the Study of Language Attrition [J]. Psychological Science, 2004, (4).

[7] Jessner U. Metalinguistic Awareness in Multilingual: Cognitive Aspects of Third Language Learning[J]. Language Awareness, 1999, ( 8).

[8] Zeng Li. A Discussion of Foreign Language Education in Ethnic Minority Regions from the Perspective of Trilingual Acquisition [J]. Journal of Research on Education for Ethnic Minorities, 2012, (1)3133.

[9] Yuan Yichuan, etc. Trilingual Education and Foreign Language Education Planning of Cross-border Ethnic Minorities in Yunnan, China[J]. Journal of Yunnan Normal University (Philosophy and Social Science Edition), 2013, (11)24.

[10] Lv Wanying, Luohon. A Study on The Problems and Countermeasures of Minorities' Foreign Language Education[J].Journal of South-Central University for Nationalities( Humanities and Social Sciences),2012,(9). 